\title{
Risk factors for ischaemic heart disease in British men
}

\author{
A G SHAPER, S J POCOCK \\ From the Department of Clinical Epidemiology and General Practice, Royal Free Hospital School of \\ Medicine, London
}

Being "top of the league" may be heartwarming for footballers but in the world of ischaemic heart disease it brings cold comfort. Northern Ireland, Scotland, and England and Wales are currently among the leaders for mortality rates from ischaemic heart disease both for men and women. While some countries, such as the United States, Australia, Canada, and New Zealand, have shown impressive declines in mortality rates for men over the past decade or so, the rates in the United Kingdom have shown little change. Improvements in the management of ischaemic heart disease, both medical and surgical, have considerably alleviated the suffering of many patients, but they are unlikely to bring about major reductions in the overall population risk of death or disability from ischaemic heart disease. We have become accustomed to being a high risk community and we can either continue in this frame of reference or we can recognise that a national policy for the prevention of ischaemic heart disease is needed urgently.

The administration of lime juice to prevent scurvy and the removal of the Broad Street pump handle to stop the spread of cholera are much quoted examples of successful action that preceded "adequate" information about a health hazard. The complexity of ischaemic heart disease and the controversies surrounding its aetiology and management, however, have raised the level of certainty demanded before action can be taken. Even though national committees of many countries have produced reports recommending action in various directions-almost all affect diet, cigarette smoking, blood pressure, and physical activity-there is still considerable argument about the extent to which these measures would affect the impact of ischaemic

Requests for reprints to Professor A G Shaper, Department of Clinical Epidemiology and General Practice, Royal Free Hospital School of Medicine, Rowland Hill Street, London NW3 2PF. heart disease in our own community. Any rational approach to preventive action in the United Kingdom requires adequate information about the nature of ischaemic heart disease in this country. Much sound epidemiological data have already been provided by American studies such as Framingham ${ }^{1}$ and by the study of London-based civil servants in Whitehall. ${ }^{2}$ A more complete insight into the problem would require information on the prevalence and development of ischaemic heart disease in a representative sample of the whole British population of middle aged men. Accordingly, the British Regional Heart Study was initiated in 1978 as a prospective study of ischaemic heart disease in 7735 men aged 40-59 drawn at random from general practice registers in 24 towns in England, Wales, and Scotland. The aims of the study were: (a) to determine the reasons for the considerable geographic variation in mortality rates from ischaemic heart disease; $(b)$ to provide information on the prevalence and incidence rates of the disease in British men; (c) to measure the effect of various factors (both personal and environmental) on the risk of developing ischaemic heart disease; $(d)$ to relate this information to policies for the prevention and control of ischaemic heart disease.

It is perhaps necessary to remind readers that no national data of this kind were available and that most previous studies were only of specific occupational groups. The British Regional Heart Study provided a sample representing all socioeconomic classes and included men irrespective of their health or employment status. After extensive intial screening in 1978-80 all 7735 men have been followed for subsequent development of ischaemic heart disease, both fatal and non-fatal. Some men have moved from the original 24 practices, so that contact has had to be maintained with 800 additional practices. At their fifth year in the study $98 \%$ of 
surviving men satisfactorily completed a questionnaire on their risk factors, and health status. ${ }^{3}$ As of July 1985, 336 men have had a major ischaemic event of which nearly half were fatal.

\section{Prevalence of ischaemic heart disease}

One in four of these middle aged men had some evidence of ischaemic heart disease at the initial examination. This was based on the World Health Organisation chest pain questionnaire and a resting electrocardiogram. ${ }^{4}$ The prevalence of ischaemic heart disease varied between towns, from $17 \%$ (Lowestoft) to $30 \%$ (Merthyr Tydfil). There was a strong correlation between these prevalence rates and the mortality rates for ischaemic heart disease derived from official sources. This suggests that the geographic inequalities in mortality rates from ischaemic heart disease are genuine and not simply due to differences in case-fatality rates.

Unrecognised or silent myocardial infarction seems to be a genuine and highly underestimated problem. Only half of those with definite myocardial infarction on electrocardiogram had ever experienced chest pain suggestive of angina or possible myocardial infarction. Furthermore, only one in five of those with evidence of ischaemic heart disease could recall such a diagnosis having been made by a doctor and these were overwhelmingly the most seriously affected. ${ }^{5}$ This low level of awareness of existing symptoms and signs among patients and doctors may account for the common belief that major ischaemic episodes "come from the blue". Little wonder that anticipatory care is not common.

\section{Risk factors}

The British Regional Heart Study has provided a national view of many established and potential risk factors for ischaemic heart disease among middle aged men. ${ }^{6-8} \mathrm{~A}$ notable finding has been the very wide range of mean blood pressures observed, from $136 \mathrm{~mm} \mathrm{Hg}$ systolic in Guildford and Shrewsbury to $153 \mathrm{~mm} \mathrm{Hg}$ in Dunfermline. ${ }^{6}$ In individual men, age, body mass index, and alcohol intake were important determining factors, with body mass index affecting blood pressure to a much greater extent than alcohol. Despite earlier claims by others that exposure to lead may have a hypertensive effect, blood lead concentrations did not appear to be a determinant of blood pressure in these British men. ${ }^{9}$ Further studies to explore these regional differences in blood pressure are under way to find out why blood pressure rises with age and why it does so at different rates in the various towns.

Cigarette smoking also differed considerably between towns, from $12 \%$ smoking 20 or more per day in Guildford to $36 \%$ in Grimsby. ${ }^{7}$ Although manual workers consistently had higher rates of $\stackrel{\vec{\oplus}}{\vec{\rho}}$ cigarette smoking than non-manual workers, the difference in smoking rates between towns was more apparent than the differences between the social $\frac{\sigma}{\sigma}$ classes within the towns. Town "culture" may play a more crucial role in determining smoking (and drinking) rates than socioeconomic class. Rates of cigarette smoking were lowest in men who were light drinkers (1-2 drinks per day) and this may in part explain the reported lower risk of ischaemic heart disease in light drinkers.

The mean concentration of serum total cholesterol did not vary much between towns and did not relate to the town levels of ischaemic heart disease mortality. Although the observation brings some joy to those weary of or opposed to the "blood cholesterol 은 story", it must be pointed out that the serum total $\overrightarrow{ }$ cholesterol concentrations are uniformly high throughout Britain (mean $6.3 \mathrm{mmol} / \mathrm{l})^{8}$ and are considerably higher than concentrations in the United States. ${ }^{10}$ The important message to be deduced from the British concentrations of serum total cholesterol is that we are a nation at considerable risk of ischaemic heart disease.

\section{Risk of ischaemic heart disease}

The first follow up analysis of major events in these British men confirms that the three most important risk factors are serum total cholesterol, cigarette smoking, and blood pressure. ${ }^{11}$ Serum total cholesterol has a continuous positive association with risk of ischaemic heart disease, and men with high concentrations $(>7.2 \mathrm{mmol} / \mathrm{l})$ had three times the risk of men with low levels $(<5.5 \mathrm{mmol} / \mathrm{l})$. Of more importance is the observation that men with average concentrations (the typical British "man in the $\delta$ street") have double the risk of a major ischaemic $₹$ event than those with lower concentrations of serum 웅 total cholesterol. This means that $60 \%$ of middle aged British men are at increased risk of ischaemic heart disease solely because of their serum total cholesterol concentrations.

Current cigarette smokers had the expected three- $N$ fold increase in risk compared with men who had $\underset{\omega}{N}$ never smoked and there was a clear gradient of $\sigma$ relation with the amount smoked. The observation ${ }_{0}$ that risk was also increased in ex-cigarette smokers $\underset{\mathbb{D}}{\overparen{D}}$ (to at least twice that in those who had never $\stackrel{?}{?}$ smoked) is also of considerable importance.

Systolic and diastolic blood pressure were both important in predicting a major event and we sym- $\stackrel{\mathbb{D}}{\mathbb{D}}$ pathise with those who wonder why the diastolic $\frac{\mathbb{}}{\mathscr{O}}$ pressure receives so much more attention in routine 0 
clinical practice. Work in progress on British Regional Heart Study data strongly indicates that systolic blood pressure alone is a far more reliable predictor of risk of cardiovascular disease than diastolic blood pressure alone. Men with systolic blood pressures just below the usually accepted levels of hypertension $(148-160 \mathrm{~mm} \mathrm{Hg}$ ) still had a twofold higher risk of a heart attack than men with lower blood pressures. This emphasises the importance of regarding blood pressure as a continuously distributed variable and also highlights the widespread nature of this risk factor in British men.

Overweight (body mass index), serum triglycerides, and high density lipoprotein (HDL) cholesterol were not predictive of risk after allowance for the other factors had been made by multivariate analysis. This is not to say that they are not important in the development of ischaemic heart disease but merely that their importance as predictors is ultimately overshadowed by other factors. The risk of a heart attack is twice as high in overweight men as in lean men, but this can be attributed to their raised concentrations of serum total cholesterol and blood pressure at screening which outrank, in statistical terms, the presence of overweight. Nevertheless, it is evident that longterm overweight and its determinants must have been critical in the ultimate development of risk. We need to find better ways of expressing the importance of factors such as overweight that at present lose their importance in the process of multivariate analysis.

\section{High density lipoprotein cholesterol}

As in other prospective studies, the risk of a heart attack in British men with the lowest concentrations of HDL cholesterol $(<0.93 \mathrm{mmol} / \mathrm{l})$ is twice that in men with higher concentrations $(>1.06 \mathrm{mmol} / \mathrm{l})$. HDL cholesterol is negatively associated with cigarette smoking and with non-HDL cholesterol, both of which have much stronger positive associations with the risk of major ischaemic heart disease events. Thus in multivariate analysis, HDL cholesterol does not emerge as having independent predictive ability. ${ }^{12}$ Although at first sight this seems at odds with the importance accorded to HDL cholesterol by other workers, comparison with six other prospective studies suggests that the findings of the British Regional Heart Study are similar to those of almost all other studies. All show that HDL cholesterol concentrations are lower in men with ischaemic heart disease than in other men, but only in Tromso, the first and the smallest of the studies, is the effect a striking one. It seems likely that closer attention to the concurrent effect of other factors on HDL cholesterol and on the risk of ischaemic heart disease may reduce the predictive importance of HDL cholesterol in these studies. The response to these "discrepant" findings has been vigorous, and criticism has been focused on the precision of measurement of HDL cholesterol and other methodological issues. ${ }^{1314}$ In reply, attention has been drawn to the internal consistency of the data, with HDL cholesterol in the British Regional Heart Study showing the same relation to alcohol, smoking, body mass index, triglyceride, and non-HDL cholesterol as seen in other studies. ${ }^{14}$ There is no doubt that low HDL cholesterol is a risk factor for ischaemic heart disease, albeit not an independent one, and equally no doubt that HDL cholesterol is a critical factor in lipid transport and thus in the development of ischaemic heart disease. What is in question is its independent ability to predict heart attacks and to "protect" against such events.

\section{Other risk factors}

Thus far, attention has been focused on the standard risk factors. Now that all men have completed at least five years follow up a further analysis of the considerably increased number of major ischaemic heart disease events allows for a full evaluation of other risk factors. These include family history, diabetes mellitus, serum glucose and uric acid concentrations, personality characteristics (type A), physical activity, electrocardiographic findings, alcohol intake, respiratory disease, blood groups, and a wide range of biochemical and haematological measurements. We have already found a way of using the relatively simple information available on physical activity to derive a score that is related to the occurrence of heart attacks. Whether this will survive the rigorous assault of multivariate analysis remains to be seen. The data on alcohol intake are of particular importance because intake has been validated against 24 biochemical and haematological measurements. ${ }^{15}$ Our preliminary findings do not support the claim that regular moderate alcohol consumption has a protective effect against ischaemic heart disease.

\section{Risk factors and pre-existing ischaemic heart disease}

There is considerable controversy about whether the established risk factors continue to exert an influence in those men in whom evidence of ischaemic heart disease has already developed. There is no doubt that the presence of ischaemic heart disease in terms of angina, previous myocardial infarction, or electrocardiographic abnor- 
malities (ischaemia, infarction) constitutes a considerable risk for a subsequent major event. Logically, therefore, the independent predictive role of the risk factors (serum total cholesterol, smoking, blood pressure) must be proportionately reduced in those with pre-existing ischaemic heart disease. In the British Regional Heart Study men with and without pre-existing ischaemic heart disease who became "cases" (that is manifested major ischaemic heart disease events) had similar levels of risk factors, which suggests that these factors continue to exert an influence in all subjects. ${ }^{11}$ Furthermore, men with pre-existing ischaemic heart disease who did not become "cases" had lower levels of systolic and diastolic blood pressure, body mass index, serum total cholesterol, trigylcerides, and percentage current cigarette smokers and higher concentrations of HDL cholesterol than men with pre-existing ischaemic heart disease who became "cases". When the men with and without pre-existing ischaemic heart disease were separated, multivariate analysis showed that some established risk factors (total cholesterol, blood pressure) continued to make an important independent contribution to risk. This implies that attention to these risk factors could be of importance in reducing subsequent risk in men who already have evidence of heart disease. Support for this concept is found in the Belgian Heart Disease Prevention Project, where the results of multifactorial intervention were strikingly more effective in men with electrocardiographic evidence of ischaemia at baseline examination than in men with a normal electrocardiogram at baseline. ${ }^{16}$

\section{Ischaemic heart disease without risk factors?}

A view that is widely held by cardiologists is that they see many patients with major ischaemic events who do not have identifiable risk factors. In the British Regional Heart Study at least a twofold independent increase in risk was associated with any one of the following criteria: (a) serum total cholesterol $\geqslant 6 \mathrm{mmol} / \mathrm{l}$, (b) systolic blood pressure $\geqslant 148 \mathrm{~mm} \mathrm{Hg}$ or diastolic blood pressure $\geqslant 93 \mathrm{~mm} \mathrm{Hg}$, or (c) current cigarette smoking. Only five of the 202 cases of ischaemic heart disease had none of these risk criteria and in over two thirds at least two criteria were present. ${ }^{11}$ Of the five men with none of the above criteria present, three had evidence of pre-existing ischaemic heart disease. The belief that major ischaemic heart disease occurs not infrequently in the absence of identifiable risk factors is perpetuated by a failure to recognise that even moderate increases in blood lipids and blood pressure carry an excess risk of ischaemic heart disease, especially if a man smokes cigarettes.

\section{Identifying men at high risk}

The ultimate aim of the British Regional Heart $\overrightarrow{\bar{s}}$ Study is to help to reduce the impact of ischaemic heart disease on our society, and currently a major $\frac{\square}{0}$ issue is what action should we take in response to the $\frac{\bar{\sigma}}{\sigma}$ current epidemic of ischaemic heart disease. $\bar{D}$ Although there is growing agreement that many major changes in lifestyle are required, with changes $\$$ in diet, cigarette smoking, and physical activity, $\vec{\circ}$ there is an awareness that such changes as we are $\vec{\overrightarrow{ }}$ likely to make in the foreseeable future are unlikely $\omega_{\sigma}$ to lead to dramatic or immediate changes in our present high rates of ischaemic heart disease mor- ot tality. We have therefore used the British Regional. Heart Study data to explore the possibility of identifying those at highest risk of major ischaemic heart $\vec{P}$ disease events, so that they may receive appropriate $\frac{}{S}$ medical care. A relatively simple method has been $\overrightarrow{-}$ devised which does not require measurement of blood lipids or electrocardiography and can be readily carried out on an opportunistic basis in gen- $\stackrel{2}{2}$ eral practice and in other situations, including cardi- $\vec{\circ}$ ology clinics. ${ }^{17}$ All that is required is a knowledge of $\underset{\infty}{\infty}$ whether the man has been told by a doctor that he * has ischaemic heart disease (angina, myocardial infarction) or diabetes or both and whether a parent has died of "heart trouble". In addition, blood pressure and the number of smoking years need to be determined. From this information a score can be calculated and compared with various cut off points $\overrightarrow{\vec{O}}$ derived from the British Regional Heart Study. This 3 system will identify a group of men, the top $20 \%$ of the overall risk score distribution, in which more than half of the new episodes of major ischaemic

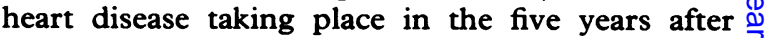
screening will occur. Addition of serum total cholesterol and electrocardiographic findings to this score 3 . only slightly improves the identification of high risk $\delta$ men and greatly increases the cost and effort of screening. It is considered that this strategy of iden- $\mathrm{O}$ tifying high risk people will be a useful complement to the population approach of changing life styles, and will help to prevent premature deaths and to increase public and professional awareness of the $\sigma$ size of the problem and the need for preventive $N$ action.

Geographical variations in ischaemic heart disease

Some of the initial impetus for the British Regional Heart Study came from a concern that the quality of drinking water (for example its hardness) was an important and potentially modifiable risk factor in $\mathbb{D}$ ischaemic heart disease and one which might 
account for the considerable regional variation in mortality from ischaemic heart disease. We have shown that water hardness is independently associated with ischaemic heart disease mortality rates to about the same extent as temperature, rainfall and socioeconomic status. ${ }^{18}$ The magnitude of the effect is small compared with the effects of other risk factors such as cigarette smoking or blood pressure. Although the water story plays some small role in regional variations in ischaemic heart disease mortality, such variations are explained to a greater extent by the regional differences in cigarette smoking and blood pressure levels. ${ }^{19}$

One of the most interesting findings in the British Regional Heart Study has been the difference in mean blood pressure levels between towns. This is associated with corresponding differences in the rates of systolic and diastolic hypertension, of doctor-diagnosed hypertension, and of regular treatment for high blood pressure. The reasons for differences in blood pressure levels and rates of hypertension between communities has usually been explored on an international basis and this leads to major methodological problems. The nomads of northern Kenya and the highlanders of New Guinea (with low blood pressures) differ from the inhabitants of New York or London (with high blood pressures) in too many ways to allow causality to be readily attributed to any of the differences observed between these very disparate groups. The British Regional Heart Study provides an opportunity to explore the inter-town differences within Britain. The intention is to determine at what age the blood pressure levels in these different communities diverge from one another and what factors, personal or environmental, feature in this divergence.

\section{Conclusion}

There have been remarkable achievements in both the medical and surgical aspects of cardiology that excite the imagination and stir enthusiasm for further high technology developments. To suggest that these achievements are irrelevant to the persistently high incidence of ischaemic heart disease seems ungrateful. Attempts to prevent ischaemic heart disease do not inspire the same fervour; there are no immediate rewards for individuals or communities. The outcome of any prevention policy is likely to be a very gradual decrease in a risk that has become accepted as normal. There will be no moment for flags or trumpets. In media terms, a man with a transplanted heart far outranks the unidentifiable man who has avoided a heart attack because of preventive measures.

There is no simple answer to the prevention of ischaemic heart disease and each country will encounter different problems, depending on the distribution of the major risk factors and on varying public and professional attitudes. Each country needs to establish the magnitude and the nature of its own ischaemic heart disease problem, although it will derive considerable benefit from the experience and findings of studies carried out elsewhere. The evidence accumulating from all sources strongly suggests that the standard risk factors, serum total cholesterol, cigarette smoking, and blood pressure, play an overwhelming role in determining the incidence of ischaemic heart disease. Attempts to reduce the incidence by lowering serum total cholesterol or blood pressure in middle aged men, however, have met with limited success and certainly do not inspire doctors to vigorous action. The natural history of ischaemic heart disease strongly implicates the duration of exposure to the risk factors, and it seems likely that major changes in the incidence of ischaemic heart disease may require major changes in diet, smoking behaviour, and physical activity from an early age, as well as the prevention of hypertension. If we are to achieve these major changes, a sound national data base on risk factors for ischaemic heart disease is required in order to influence the public, doctors, and other professionals in their clinical and community work, and the legislators and administrators who provide and manage our resources. The data base may change from time to time, so that reassessment at regular intervals may be necessary. Attempts are being made to do so through the Monica studies ${ }^{20}$ and through the Scottish Heart Health Study and Heartbeat Wales. All of these will contribute to a better understanding and to decisions on appropriate action.

\section{References}

1 Dawber TR. The Framingham Study. The epidemiology of atherosclerotic disease. Cambridge, Massachusetts: Havard University Press, 1980.

2 Rose G, Reid DD, Hamilton PJS, McCartney P, Keen $\mathrm{H}$, Jarrett RJ. Myocardial ischaemia, risk factors and death from coronary heart disease. Lancet 1977;i:105-9.

3 Walker M, Shaper AG. Follow-up of subjects in prospective studies in general practice. $\mathscr{f} R$ Coll Gen Pract 1984;34:365-70.

4 Shaper AG, Cook DG, Walker M, Macfarlane PW. Prevalence of ischaemic heart disease in middle aged British men. Br Heart f 1984;51:595-605.

5 Shaper AG, Cook DG, Walker M, Macfarlane PW. Recall of diagnosis by men with ischaemic heart disease. Br Heart $\mathcal{F}$ 1984;51:606-11.

6 Shaper AG, Pocock SJ, Walker M, Cohen NM, Wale 
CJ, Thomson AG. British Regional Heart Study: cardiovascular risk factors in middle aged men in 24 towns. Br Med F 1981;282:179-86.

7 Cummins RO, Shaper AG, Walker M, Wale CJ. Smoking and drinking by middle aged British men: effects of social class and town of residence. $\mathrm{Br} \mathrm{Med} \mathcal{F}$ 1981;283:1497-502.

8 Thelle DS, Shaper AG, Whitehead TP, Bullock DG, Ashby D, Patel I. Blood lipids in middle-aged British men. Br Heart $\mathcal{F}$ 1983;49:205-13.

9 Pocock SJ, Shaper AG, Ashby D, Delves T, Whitehead TP. Blood lead concentration, blood pressure, and renal function. $\mathrm{Br} \mathrm{Med} \mathcal{F}$ 1984;289:872-4.

10 Shaper AG, Pocock SJ. British blood cholesterol values and the American consensus. $\mathrm{Br} \mathrm{Med} F \mathrm{f}$ 1985;291: 480-1.

11 Shaper AG, Pocock SJ, Walker M, Phillips A, Whitehead TP, Macfarlane PW. Risk factors for ischaemic heart disease: the prospective phase of the British Regional Heart Study. I Epidemiol Community Health 1985;39:197-209.

12 Pocock SJ, Shaper AG, Phillips AN, Walker M, Whitehead TP. High density lipoprotein cholesterol is not a major risk factor for ischaemic heart disease in British men. Br Med $\mathcal{F}$ 1986;292:515-9.
13 Anonymous. HDL and ischaemic heart disease in Britain. Lancet 1986;i:481-2.

14 Miller NE; Wynn V, et al; Pocock SJ, et al. HDL- $\overrightarrow{\vec{F}}$ cholesterol is not a major risk factor for ischaemic $\stackrel{\oplus}{+}$ heart disease in British men [Letters]. $\mathrm{Br}$ Med $\mathfrak{f}^{\circ}$ 1986;292:1012-4.

15 Shaper AG, Pocock SJ, Ashby D, Walker M, White- $\bar{\omega}$ head TP. Biochemical and haematological response $\mathbb{D}$ to alcohol intake. Ann Clin Biochem 1985;22:50-61.

16 Kornitzer M, De Backer G, Dramaix M, et al. Belgian के heart disease prevention project: incidence and $\vec{O}$ mortality results. Lancet 1983;i:1066-70.

17 Shaper AG, Pocock SJ, Phillips AN, Walker M. Iden- $\vec{c}$ tifying men at high risk of heart attacks: a strategy for use in general practice. $\mathrm{Br} \mathrm{Med} \mathcal{F}$ 1986;293:474-9.

18 Pocock SJ, Shaper AG, Cook DG, et al. British or Regional Heart Study: geographic variations in car- : diovascular mortality, and the role of water quality. Br Med F 1980;280:1243-9.

19 Shaper AG. Geographic variations in cardiovascular 윽 mortality in Great Britain. Br Med Bull 1984;40: 366-73.

20 Tunstall-Pedoe $H$. Monitoring trends in cardiovascular disease and risk factors: the WHO "Monica" project. WHO Chron 1985;39:3-5. 